Abstract P3.177 Table 1 Table to show sexual behaviour \& new diagnoses of STI/blood borne viruses (BBV)

\begin{tabular}{|c|c|c|c|c|c|}
\hline No. sexual contacts $<3$ months & No. patients (\%) & Reported sexual behaviour & No. patients (\%) & STI/BBV & No. of new diagnoses (\%) \\
\hline 0 & $2(3.4 \%)$ & MSM UPAI < 1wk & $14(31.8 \%)$ & CT & $5 / 59(8.5 \%)$ \\
\hline 1 & $14(23.7 \%)$ & MSM UPAI $<1 \mathrm{~m}$ & $20(45.4 \%)$ & $\mathrm{GC}$ & $3 / 59(5.1 \%)$ \\
\hline $2-5$ & $21(35.6 \%)$ & MSM UPAI $<3 \mathrm{~m}$ & $30(68.1 \%)$ & HPV & $1 / 59(1.7 \%)$ \\
\hline $6-10$ & $8(13.6 \%)$ & Group sex/sex parties/anon. sex & $15(25.4 \%)$ & Scabies & $1 / 59(1.7 \%)$ \\
\hline $11-20$ & $5(8.4 \%)$ & IVDU & $15(25.4 \%)$ & PID & $1 / 59(1.7 \%)$ \\
\hline $21-50$ & $2(3.4 \%)$ & CSW & $7(11.9 \%)$ & HIV & $1 / 31 *(3.2 \%)$ \\
\hline$>50$ & $3(5.1 \%)$ & Fisting & $1(1.7 \%)$ & Hep B & $1 / 28 *(3.6 \%)$ \\
\hline $\begin{array}{l}\text { Unknown/"too many to count" } \\
\text { Median = } 3\end{array}$ & $4(6.8 \%)$ & & & $\begin{array}{l}{ }^{*} \text { denominator is number } \\
\text { accepting the test }\end{array}$ & \\
\hline
\end{tabular}

need to implement the respective tests routinely, preferably at their workplace. Final data is expected to confirm the present results.

\section{P3.177 SEXUAL HEALTH SCREENING IN A CLUB DRUG CLINIC}

doi:10.1136/sextrans-2013-051184.0634

K Stegmann, K Cook, D Payne, L Watson, J Hardie, 0 Bowden-Jones, A Sullivan, S Day. Chelsea and Westminster Hospital, London, UK

Background The Club Drug Clinic (CDC) is a service established in 2010 for the increasing numbers of adults who have developed problems with club drugs. Use of these drugs is associated with high risk sexual behaviour and an increased risk of acquiring HIV and sexually transmitted infections (STIs). We provide an opportunistic sexual health screening service to clients in the CDC. This study aims to identify the STI rates amongst our attendees.

Methods Notes review of clients seen in our CDC sexual health service from June 2011 to January 2013.

Results 59 clients were seen in the sexual health clinic, receiving an average of 1.2 screens per client. Eight clients were female $(13 \%)$ and 51 male (87\%) (44 (75\%) MSM). Median age was 32 (21-55) yrs.

Thirteen STIs were identified from seventy STI screens. STI prevalence was $19 \%(11 / 59)$. Clients reported their last STI screen to be: < 3 months $17(29 \%) ;<6$ months $29(49 \%) ;<1$ year $38(64 \%)$, never 1 , unsure $11(18.6 \%)$.

$21(36 \%)$ clients were HIV positive (1 new diagnosis). Of these, 11 (52\%) were on ARVs, with 10/11 having a HIV viral load (VL) $<40$ copies/ml. Median HIV VL for those not on ARV was 107,170 copies/ml (range 1164 to 23 million).

Discussion Despite many clients reporting recent STI screens this study demonstrates high risk sexual behaviour and a significant prevalence of STI's and HIV amongst CDC attendees. These findings support the on-going and regular provision of sexual health screening to CDC clients. Given this was a self-referring group representing 59/360 (16\%) total CDC attendees more work is need to encourage other CDC clients to attend for STI screens and to recall existing sexual health clinic attendees for repeat HIV/STI testing.

\section{P3.178 SYPHILIS PREVALENCE IN THE MIDDLE EAST AND NORTH AFRICA: A SYSTEMATIC REVIEW}

doi:10.1136/sextrans-2013-051184.0635

'S K Riome, ${ }^{1,2,3}$ L J Abu-Raddad. 'Weill Cornell Medical College - Oatar, Doha, Qatar; ${ }^{2}$ Weill Cornell Medical College, Cornell Univeristy, New York, NY, United States; ${ }^{3}$ Fred Hutchinson Cancer Research Center, Seattle, WA, United States

Background There is limited knowledge regarding the extent of the disease burden of syphilis in the Middle East and North Africa
(MENA) region. The objective of this study was to provide, for the first time, a review of the prevalence of syphilis in the MENA region. Methods A systematic review of all available data on syphilis prevalence in 23 countries in MENA was conducted following the PRISMA guidelines. Sources of data included PubMed and Embase databases which were searched with no restrictions on time or language. Identified records were screened for relevance and eligibility. All studies with a prevalence measure of syphilis were eligible for inclusion irrespective of study design.

Results The search yielded 383 records out of which 98 articles were found eligible for inclusion. Results were classified and analysed according to three defined population risk groups: High-risk, intermediate-risk, and general population (low risk). High-risk populations had the following prevalence levels: female sex workers $(1 \%-87 \%)$, men who have sex with men $(4 \%-60 \%)$, male sex workers (4\%-63\%) and injecting drug users (1\%-18\%). Select intermediate risk groups had the following prevalence levels: STD clinic attendees $(1 \%-33 \%)$, prisoners $(0 \%-23 \%)$, and truck drivers $(4 \%-$ $7 \%)$. Select general population groups had the following prevalence levels: blood donors (0\%-3\%) and ANC attendees (0\%-19\%).

Conclusions The quality of studies and their designs varied and diagnostic methods were not always clear. High prevalence levels were identified among high-risk populations, and relatively high levels were also found among intermediate risk groups. Low prevalence levels however were documented among general population groups. Though the overall prevalence of syphilis in MENA may not be large, there is still significant burden of disease that needs to be addressed. Given the limitations in available data, further studies are needed to better characterise the infection trends.

\section{P3.179 PREVALENCE OF HIV AND SYPHILIS AND SOCIAL BEHAVIOUR CHARACTERISTICS OF NATIVE POPULATIONS IN THREE GEOGRAPHICAL AREAS OF PARAGUAY - 2011}

\section{doi:10.1136/sextrans-2013-051184.0636}

${ }^{1} \mathrm{~N}$ Aguayo, 'G Aguilar, 'L Gimenez, ${ }^{1} \mathrm{~A}$ Barboza, ${ }^{2} \mathrm{P}$ Martinez, ${ }^{3} \mathrm{G}$ Estigarribia, ${ }^{1} \mathrm{~A}$ Kawabata. 'National Program of Control of HIVAidsSTI, Asuncion, Paraguay; ${ }^{2}$ National University of Caaguazu, Caaguazu, Paraguay; ${ }^{3}$ National University of Caaguazu, Asuncion, Paraguay

Background The indigenous population presents cultural, socioeconomic characteristics that increases its vulnerability to sexually transmitted infections, like syphilis and HIV.

Methods Cross-sectional descriptive study, with confidential linked serological tests for HIV and Syphilis, carried out in three geographical areas of Paraguay (Chaco, Center-eastern and metropolitan Area) during 2011. A probabilistic, stratified, two-stage cluster samplingwas carried out. Syphilis was tested with Rapid Test and VDRL. HIV included ELISA and Western Blot for confirmation. 
Results one thousand three hundred twenty two indigenous participants were surveyed, sixty three \% were female, fifty five $55 \%$ less than thrirty five 35 years old. Syphilis prevalence was $9.7 \%$ (IC95\%: $8.2-11.5$ ) and that of HIV $0.4 \%$ (IC95\%: $0.40-1.0$ ). There was a difference between those diagnosed with HIV $<25$ years old: $0.6 \%$ (IC $0.5-1.2$ ) and $>25$ years old: $0.3 \%$ (IC $0.3-0.8$ ). Differences in syphilis prevalence among men (10.1\%) and women $(9.7 \%)$ weren't significant $(p=0.83)$. Seventy five $75 \%$ of the population initiated sexual relations < fifteen 15 years old. Condom use was $5.9 \%$.twenty one $21.2 \%$ reported having more than two sexual partners in the past year; in indigenous population $<25$ twenty five years old: $6.3 \%$ and $>25$ years old: $7.2 \%$ identified correctly the ways of preventing HIV infection and rejected erroneous ideas on the transmission of the virus.

Conclusions Syphilis prevalence is higher in natives than that of the general population of Paraguay; however, the HIV prevalence is similar. The low percentage of use of condom and knowledge of the syphilis and HIVare related factors that indicate the need of an urgent intervention from the national authorities to break the chain of transmission of STI in this population.

\section{P3.180 KNOWLEDGE ATTITUDE PRACTISES ABOUT SEXUALLY TRANSMITTED DISEASE AMONG THE COMMERCIAL SEX WORKERS}

doi:10.1136/sextrans-2013-051184.0637

${ }^{1} \mathbf{M}$ Karim, ${ }^{2} \mathrm{~N}$ Mona. 'National Institute of Preventive and Social Medicine (NIPSOM), Dhaka, Bangladesh; ${ }^{2}$ Bangladesh Medical college, Dhaka, Bangladesh

Objective To assess the knowledge, attitude and practises regarding STDs/RTI among the commercial sex workers.

Material and Methods It was a cross sectional study conducted among 204 commercial sex workers, residing in different places of Dhaka metropolitan city. Data were collected by questionnaire.

Results It was found that the mean age of commercial sex workers was 17.8 years. Regarding educational status, 57\% of the respondents were illiterate, $30 \%$ primary level and $13 \%$ were secondary level of education. It was found that $40 \%$ of the respondents were unmarried followed by $50 \%$ abandoned. Majority of the respondents $93 \%$ heard about STDs/RTI, but knowledge regarding STDs/RTI among the respondents was not adequate. Majority of the respondents $74 \%$ had fair knowledge followed by poor knowledge $17 \%$. Only $19 \%$ of the respondents had good knowledge. Regarding attitude, more than half of the respondents $57 \%$ agreed that STDs/RTI are harmful disease and need proper treatment followed by strongly agreed 3.6\%. About three fourth of the respondents $70 \%$ agreed that condom should be used during every sexual act followed by strongly agreed $23 \%$ and only $3 \%$ of the respondents disagreed. It was also found that $73 \%$ of the respondents needed more knowledge about STDs/RTI. Nature of the sexual practise among the commercial sex workers was per vaginal $94 \%$, only $6 \%$ of the respondents reported oral sex either forceful or taking high money.

Conclusion The magnitude of the problems of STDs/RTI is an increasing public health concern in Bangladesh. It was evident that preventive measures among them were inadequate. It was clear that most of the commercial sex workers having STDs did not seek medical treatment. Provision of appropriate health information with focus on health education improves their knowledge about STDs/ RTI with its symptoms, prevention and hygienic practise.

\section{P3.181 THE ASSOCIATION BETWEEN ALCOHOL USE AND SEXUALLY TRANSMITTED INFECTION(STI) INCIDENCE AMONG KENYAN WOMEN ENGAGED IN TRANSACTIONAL SEX}

doi:10.1136/sextrans-2013-051184.0638
K S Wilson, ${ }^{2} \mathrm{~K}$ Odem-Davis, ${ }^{3} \mathrm{~F}$ Kashonga, ${ }^{3} \mathrm{G}$ Wanje, ${ }^{3} \mathrm{~W}$ Jaoko, ${ }^{3} \mathrm{~B}$ Estambale, ${ }^{1} \mathrm{R}$ McClelland. 'University of Washington, Seattle, WA, United States; ${ }^{2} F r e d$ Hutchinson

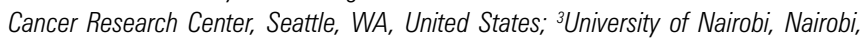
Kenya

Background Few prospective studies have examined the association between alcohol use and sexually transmitted infections (STI) among African women. We evaluated whether alcohol use was associated with increased risk of STI in a cohort of Kenyan women.

Methods We analysed data from a prospective study of women who report transactional sex in Mombasa. Women 18 and older who enrolled between 2006 and 2011 were included. Participants could contribute up to two years of follow-up. Baseline alcohol use was categorised as none, 1-7, or $\geq 8$ drinks/week. STIs (gonorrhoea, Chlamydia, and Trichomonas) and sexual risk behaviours were assessed monthly. The association between alcohol use and any STI was evaluated by logistic regression using generalised estimating equations.

Results Overall, 622 women contributed 368 person-years of observation. Of these, 161(25.8\%) were HIV-positive. Among HIVpositive women, 88 (54.7\%) reported 1-7 drinks/week and 31 $(19.3 \%)$ reported $\geq 8$ drinks/week. Among HIV-negative women, $248(53.8 \%)$ reported $1-7$ drinks/week and $100(21.7 \%)$ reported $\geq 8$ drinks/week. The association between alcohol use and STI risk was significantly different in HIV-positive compared to HIV-negative women $(p=0.05)$. Alcohol use was associated with STI acquisition only in HIV-positive women. Compared to non-drinkers, women who drank 1-7 drinks (odds ratio $[\mathrm{OR}]=2.3[1.0-5.5]$ ) and $\geq 8$ drinks/week $(\mathrm{OR}=3.2[1.0-10.6])$ had increased risk of STI. These associations were similar though no longer statistically significant after adjusting for age, workplace and marijuana use (1-7 drinks $\mathrm{OR}=2.3[1.0,5.3] ; \geq 8$ drinks $\mathrm{OR}=2.0[0.7,6.1]$ ).

Conclusion In this prospective analysis, baseline alcohol use was associated with an increased risk of STI among HIV-positive women. Addressing alcohol use problems in HIV care settings may offer additional benefits of reducing the burden of STIs among highrisk African women. Future research with time-varying measures of alcohol use will be important to further characterising the relationships between alcohol and STI risk in this population.

\section{P3.182 SEXUALLY TRANSMITTED INFECTION SCREENING AMONG HIV-NEGATIVE MEN AND WOMEN SEEKING HIV-TESTING ONLY: MISSED OPPORTUNITY FOR HIV PREVENTION?}

doi:10.1136/sextrans-2013-051184.0639

${ }^{1}$ R C Perkins, ${ }^{2} \mathrm{G}$ Douglass, ${ }^{2} \mathrm{~V} T a,{ }^{1} \mathrm{~A}$ Dright, ${ }^{2} \mathrm{M}$ Fomundam, ${ }^{3} \mathrm{Y} \mathrm{Li},{ }^{3} \mathrm{M}$ Plankey. ${ }^{1}$ WhitmanWalker Health, Washington, DC, United States; ${ }^{2}$ George Washington Unviersity School of Public Health, Washington, DC, United States; ${ }^{3}$ Georgetown University Medical Center, Department of Medicine Division of Infectious Diseases, Washington, DC, United States

Background Sexually transmitted infections (STIs) increase the risk of HIV infection; however concurrent HIV and STI testing may not be available in all clinical settings. In previous work, we showed a high concordance of self vs. provider STI testing. In this study, we evaluated the implementation of STI self-testing among HIV-negative, asymptomatic adults.

Methods Self collected urine, throat and/or rectal swabs for Chlamydia trachomatis (CT) and Neisseria gonorrhoeae (GC), without physical examination, were completed by 514 HIV-negative (rapid HIV test performed on same day), asymptomatic adults at a walkin clinic in Washington, DC. Sociodemographic and sexual risk behaviour data were collected, and a post-testing satisfaction survey was completed by each individual.

Results The sample included: $413(80.4 \%)$ men and 101(19.6\%) women. The median age was 30 (range 15-72) years. Among the men: 135 (32.7\%) African-American; 211 (51.1\%) White; 262 